\title{
Role of Orbitofrontal Cortex Neuronal Ensembles in the Expression of Incubation of Heroin Craving
}

\author{
Sanya Fanous, Evan M. Goldart, Florence R. M. Theberge, Jennifer M. Bossert, Yavin Shaham, and Bruce T. Hope \\ Behavioral Neuroscience Branch, Intramural Research Program/National Institute on Drug Abuse/National Institutes of Health/Department of Health and \\ Human Services, Baltimore, Maryland 21224
}

In humans, exposure to cues previously associated with heroin use often provokes relapse after prolonged withdrawal periods. In rats, cue-induced heroin seeking progressively increases after withdrawal (incubation of heroin craving). Here, we examined the role of orbitofrontal cortex (OFC) neuronal ensembles in the enhanced response to heroin cues after prolonged withdrawal or the expression of incubation of heroin craving. We trained rats to self-administer heroin $(6 \mathrm{~h} / \mathrm{d}$ for $10 \mathrm{~d})$ and assessed cue-induced heroin seeking in extinction tests after 1 or 14 withdrawal days. Cue-induced heroin seeking increased from 1 to $14 \mathrm{~d}$ and was accompanied by increased Fos expression in $\sim 12 \%$ of OFC neurons. Nonselective inactivation of OFC neurons with the GABA agonists baclofen + muscimol decreased cue-induced heroin seeking on withdrawal day 14 but not day 1 . We then used the Daun02 inactivation procedure to assess a causal role of the minority of selectively activated Fos-expressing OFC neurons (that presumably form cue-encoding neuronal ensembles) in cueinduced heroin seeking after 14 withdrawal days. We trained $c$-fos-lacZ transgenic rats to self-administer heroin and $11 \mathrm{~d}$ later reexposed them to heroin-associated cues or novel cues for $15 \mathrm{~min}$ (induction day), followed by OFC Daun02 or vehicle injections 90 min later; we then tested the rats in extinction tests $3 \mathrm{~d}$ later. Daun02 selectively decreased cue-induced heroin seeking in rats previously reexposed to the heroin-associated cues on induction day but not in rats exposed previously to novel cues. Results suggest that heroin-cue-activated OFC neuronal ensembles contribute to the expression of incubation of heroin craving.

\section{Introduction}

In humans, relapse to heroin use can occur after prolonged abstinence periods and is often precipitated by exposure to cues previously associated with heroin (Wikler, 1973; O'Brien et al., 1992). In rats, cue-induced relapse to heroin seeking, as assessed in extinction and reinstatement procedures (Self and Nestler, 1998; Shaham et al., 2003), progressively increases after withdrawal from heroin (Shalev et al., 2001; Zhou et al., 2009) and other drugs (Neisewander et al., 2000; Bienkowski et al., 2004; Shepard et al., 2004; Abdolahi et al., 2010), a phenomenon termed incubation of drug craving (Grimm et al., 2001). Studies on neural mechanisms of incubation of drug craving have focused on cocaine, whereas mechanisms of incubation of heroin craving are unknown (Wolf and Ferrario, 2010; Pickens et al., 2011).

Human imaging studies demonstrated that heroin cues activate the orbitofrontal cortex (OFC) and that this activation correlates with drug craving (Sell et al., 2000; Langleben et al., 2008).

Received April 19, 2012; revised June 16, 2012; accepted July 4, 2012.

Author contributions: S.F., Y.S., and B.T.H. designed research; S.F., E.M.G., F.R.M.T., and J.M.B. performed research; S.F. analyzed data; S.F., Y.S., and B.T.H. wrote the paper.

This research was supported by the National Institutes of Health/National Institute on Drug Abuse Intramural Research Program. We thank Dr. Kenner Rice (National Institute on Drug Abuse/Intramural Research Program) for synthesizing Daun02 and Dr. Geoff Schoenbaum for helpful comments on this manuscript.

Correspondence should be addressed to Dr. Bruce T. Hope, Behavioral Neuroscience Branch, Intramural Research Program/National Institutes of Health/National Institute on Drug Abuse, 251 Bayview Drive, Baltimore, MD 21224. E-mail: bhope@intra.nida.nih.gov.

DOI:10.1523/JNEUROSCI.1914-12.2012

Copyright $\odot 2012$ the authors $\quad 0270-6474 / 12 / 3211600-10 \$ 15.00 / 0$
In rats, cue-induced heroin seeking is associated with the induction of several immediate early genes in OFC (Koya et al., 2006; Kuntz et al., 2008b), including the neuronal activity marker $c$-fos (Morgan and Curran, 1991). Reversible inactivation of the OFC decreases discrete-cue- and context-induced reinstatement of cocaine seeking in rats (Fuchs et al., 2004; Lasseter et al., 2009); to date, a role of OFC in cue-induced heroin seeking has not been similarly investigated.

Not all OFC neurons may be equally involved in drug seeking. We recently used a context-induced reinstatement procedure (Crombag et al., 2008) and found that only a small number of sparsely distributed ventral medial prefrontal cortex (mPFC) neurons are activated after exposure to the heroin-associated context (Bossert et al., 2011). We then used the pharmacogenetic Daun02 inactivation procedure (Koya et al., 2009b) to demonstrate that selective inactivation of these context-activated neurons decreases context-induced reinstatement. We proposed that a small subset of ventral mPFC neurons forms neuronal ensembles that encode learned associations between heroin reward and heroin-associated contexts and that reactivation of these neuronal ensembles by drug-associated contexts during abstinence provokes relapse (Bossert et al., 2011).

Here, we used the Daun02 inactivation procedure to determine whether OFC neuronal ensembles contribute to enhanced cue-induced heroin seeking after prolonged withdrawal or the expression of incubation of heroin craving. We use the term "cues" to encompass all external cues, including contextual and discrete cues, associated with heroin self-administration. The term "neuronal ensembles" refers to a small subset of selectively 
activated OFC neurons that encodes the learned associations between heroin reward and heroin cues that provoke drug seeking.

We first used Fos immunohistochemistry to assess activation of OFC neurons during cue-induced heroin seeking in extinction tests after 1 or 14 withdrawal days. We then assessed the effect of nonselective inactivation of OFC neurons with the GABA agonists baclofen + muscimol (McFarland and Kalivas, 2001) on cue-induced heroin seeking after 1 or 14 withdrawal days. Finally, we used the Daun02 inactivation procedure (Koya et al., 2009b) to selectively inactivate the small number of OFC neurons that express Fos in response to heroin cues to determine the role of cue-activated neuronal ensembles in enhanced cue-induced heroin seeking after 14 withdrawal days or the expression of incubation of heroin craving.

\section{Materials and Methods}

Animals. Male Sprague Dawley rats (350-400 g; total $n=170$; Charles River Laboratories) were maintained under a reverse $12 \mathrm{~h}$ light/dark cycle, with food and water available ad libitum in home cages. Rats were allowed to habituate to their home cages for at least $7 \mathrm{~d}$ before surgery. On the day of surgery, rats were anesthetized with intraperitoneal injections of Equithesin $(60 \mathrm{mg} / \mathrm{kg}$ sodium pentobarbital $+25 \mathrm{mg} / \mathrm{kg}$ chloral hydrate), and intravenous catheters were implanted as described previously (Bossert et al., 2009; Koya et al., 2009a; Lu et al., 2009). The opiate analgesic buprenorphine $(0.1 \mathrm{mg} / \mathrm{kg}$, s.c.; National Institute on Drug Abuse) was injected after surgery to decrease postsurgical pain. During recovery $(7-10 \mathrm{~d})$ and training, catheters were flushed every $24-48 \mathrm{~h}$ with sterile saline and the antibiotic gentamicin $(4.25 \mathrm{mg} / \mathrm{ml})$ to prevent infections. All procedures followed the guidelines outlined in the NIH Guide for the Care and Use of Laboratory Animals.

Heroin self-administration and extinction tests. For all experiments, rats underwent three experimental phases: heroin self-administration training, withdrawal period, and extinction tests for cue-induced heroin seeking. During the training phase, rats were trained to self-administer heroin once daily for $10 \mathrm{~d}$ while chronically housed in self-administration chambers that were located inside sound-attenuating cabinets and controlled by a MED Associates system. Each day, the rats were trained to selfadminister heroin $(0.075 \mathrm{mg} / \mathrm{kg}$ per infusion over $3.2 \mathrm{~s})$ during six 1-h sessions separated by 5 min using a fixed ratio 1 with 20 s timeout reinforcement schedule (Airavaara et al., 2011). We find that including a 5 min off period between each $1 \mathrm{~h}$ session facilitates the acquisition of heroin self-administration training. At the beginning of the training sessions, catheters were connected via a modified cannula (Plastics One) to liquid swivels (Instech) with polyethylene 50 tubing. Sessions started at the onset of the dark cycle and began with insertion of the active lever and illumination of a red house light that remained on during the sessions. Active lever presses activated the infusion pump and produced a $5 \mathrm{~s} \mathrm{light}$ cue. At the end of each $1 \mathrm{~h}$ session, the house light was turned off and the active lever was retracted. Lever presses were recorded from both the active lever and a nonretractable inactive lever that did not activate the infusion pump. Food and water was available ad libitum for all days of training. During the withdrawal phase, rats were removed from the selfadministration chambers, kept in new home cages in the animal facility for 1 or 13-15 d (referred to as $14 \mathrm{~d}$ withdrawal), and handled three times per week.

On test days, some of the rats returned to the self-administration chambers for the extinction tests, while the other rats remained in their home cages and were not exposed to the extinction tests (no test). For the extinction test groups, 90 min extinction tests were conducted under the same experimental conditions as in training, except that active lever presses were not reinforced with heroin. During the extinction tests, the rats were exposed to the heroin context, and lever presses led to contingent presentations of the discrete light cue previously paired with heroin infusions during training; this discrete cue serves as a conditioned reinforcer during the tests. Tests started at the onset of the dark cycle and began with the insertion of the active lever and illumination of the red house light that remained on for the duration of the session. Active lever presses during testing resulted in contingent presentations of the light cue that was previously paired with heroin infusions during training but not heroin.

Experiment 1: cue-induced heroin seeking and OFC neuronal activation after withdrawal. A total of 44 rats were used. The rats in the extinction test groups were killed immediately after the 90 min extinction tests (performed after 1 or 14 withdrawal days, $n=12$ and $n=9$, respectively); rats in the no-test groups were killed after 1 or 14 withdrawal days $(n=13$ and $n=10$, respectively) at the same time as their respective extinction test groups. The rats were deeply anesthetized with isoflurane and perfused with $100 \mathrm{ml}$ of PBS, followed by $400 \mathrm{ml}$ of $4 \%$ paraformaldehyde. The brains were postfixed in paraformaldehyde for $90 \mathrm{~min}$ and transferred to $30 \%$ sucrose in PBS solution at $4^{\circ} \mathrm{C}$ for $2-3 \mathrm{~d}$. Brains were frozen in powdered dry ice and kept at $-80^{\circ} \mathrm{C}$ until sectioning.

Coronal sections were cut $40 \mu \mathrm{m}$ thick between bregma +3.7 and $+2.7 \mathrm{~mm}$ (Paxinos and Watson, 2005). Free-floating sections were washed three times in PBS, blocked with $3 \%$ normal goat serum (NGS) in PBS with $0.25 \%$ Triton X-100 (PBS-Tx), and incubated $24 \mathrm{~h}$ at $4^{\circ} \mathrm{C}$ with anti-Fos antibody (sc-52; Santa Cruz Biotechnology) diluted 1:4000 in blocking solution. Sections were washed again with PBS and incubated for $2 \mathrm{~h}$ in biotinylated goat anti-rabbit secondary antibody (1:400; Vector Laboratories) in PBS-Tx and 1\% NGS. After washing in PBS, sections were incubated for $1 \mathrm{~h}$ in avidin-biotin-peroxidase complex (ABC Elite kit, PK-6100; Vector Laboratories) in PBS containing 0.5\% Triton $\mathrm{X}-100$. Finally, sections were washed in PBS and developed in 3,3'diaminobenzidine for $\sim 3 \mathrm{~min}$, transferred into PBS, and mounted onto chromalum-gelatin-coated slides. Once dry, the slides were dehydrated through a graded series of alcohol and cleared with Citrasolv (Thermo Fisher Scientific) before coverslipping with Permount (Sigma).

Bright-field images of Fos immunoreactivity in the OFC were captured using a CCD camera (Photometrics Coolsnap; Roper Scientific) and Qimaging Exi Aqua attached to a Carl Zeiss Axioskop 2 microscope. Images for counting labeled cells were captured at $50 \times$ magnification. Labeled cells from two to four hemispheres per rat were automatically counted using IPLab software for Macintosh, version 3.9.4 r5 (Scanalytics) and iVision for Macintosh, version 4.0.15 (BioVision). The sampled areas of the OFC from each hemisphere were $\sim 1.25 \mathrm{~mm}^{2}$. Counts from all images from each rat were averaged, so that each rat was an $n$ of 1 .

Experiment 2: characterization of activated OFC neurons using fluorescent double-labeling immunohistochemistry. We used double-label fluorescent immunohistochemistry to characterize OFC neurons activated during the extinction tests. For these experiments, one group of seven rats underwent the same three experimental phases as those described above. All rats were perfused with paraformaldehyde immediately after the 90-min day 14 extinction test, and their brains were processed as described above and kept at $-80^{\circ} \mathrm{C}$ until sectioning. Coronal sections were cut between bregma +3.7 and $+2.7 \mathrm{~mm}$ (Paxinos and Watson, 2005).

We determined the proportion of all OFC neurons expressing Fos during extinction testing by double labeling for Fos and the neuronspecific protein NeuN (Mullen et al., 1992). We also assessed the phenotype of Fos-expressing neurons by double labeling for Fos and calcium/ calmodulin-dependent protein kinase II (CaMKII), a marker of cortical glutamatergic pyramidal projection neurons (Liu and Jones, 1996), and glutamic acid decarboxylase 67 (GAD67), a marker of GABAergic neurons (Kaufman et al., 1986, 1991).

For Fos + CaMKII and Fos + GAD67 labeling, 30- $\mu$ m-thick sections were first washed three times in PBS. Sections were incubated for $1 \mathrm{~h}$ in a blocking solution $5 \% \mathrm{NGS}$ and $2.5 \%$ bovine serum albumin in PBS with $0.2 \%$ Triton X-100) and then incubated for $48 \mathrm{~h}$ with the anti-Fos primary antibody (rabbit, 1:400 dilution, sc-52; Santa Cruz Biotechnology) and either anti-CaMKII primary antibody (mouse, 1:100 dilution, MA1048; Pierce Biotechnology) or anti-GAD67 primary antibody (mouse, 1:1000 dilution, MAB5406; Millipore) in blocking solution. After washing, sections were incubated for $2 \mathrm{~h}$ in blocking solution with secondary antibodies Alexa Fluor 488-labeled donkey anti-rabbit (1:200 dilution, A-21206; Invitrogen) and Alexa Fluor 568-labeled goat anti-mouse antibody (1:200 dilution, A-11004; Invitrogen). Sections were then washed, 
mounted on chromalum-gelatin-coated slides, air dried, and coverslipped with Vectashield fluorescent mounting medium.

For Fos + NeuN labeling, $40 \mu \mathrm{m}$ sections were washed three times in Tris-buffered saline (TBS) and permeabilized for $30 \mathrm{~min}$ in TBS with $0.2 \%$ Triton X-100. Sections were incubated in primary antibodies diluted in TBS with $0.2 \%$ Triton X-100 for $24 \mathrm{~h}$ on a shaker at $4^{\circ} \mathrm{C}$. Primary antibodies were anti-Fos (rabbit, 1:400 dilution, sc-52; Santa Cruz Biotechnology) and biotinylated anti-NeuN (mouse, 1:2000 dilution). Sections were washed three times in TBS and incubated in secondary fluorescent labels diluted in TBS with $0.2 \%$ Triton X-100 for $2 \mathrm{~h}$ on a shaker at room temperature. Secondary antibodies were Alexa Fluor 488labeled donkey anti-rabbit (1:200 dilution, A-10042; Invitrogen) and Alexa Fluor 350-conjugated streptavidin (1:2000 dilution, S-11249; Invitrogen) to label NeuN. After labeling, sections were washed in TBS, mounted onto chromalum-gelatin-coated slides, and coverslipped with Vectashield hard-set mounting media.

All fluorescent images of OFC (3.2 mm anterior to bregma) were captured using a CCD camera (Photometrics Coolsnap; Roper Scientific) attached to a Carl Zeiss Axioskop 2 microscope. Images for colocalization of Fos and NeuN were captured at $200 \times$ magnification, whereas colocalization of other proteins was captured at $400 \times$ magnification. The number of Fos-labeled and double-labeled cells from the OFC of one section per rat were counted using iVision for Macintosh, version 4.0.15 (BioVision).

Experiment 3: effect of pharmacological inactivation of OFC on cueinduced heroin seeking. Forty-eight Male Sprague Dawley rats were anesthetized as described above and implanted with permanent bilateral guide cannulae ( 23 gauge; Plastics One) aimed $1 \mathrm{~mm}$ above the OFC. The stereotaxic coordinates were $+3.2 \mathrm{~mm}$ anteroposterior, $\pm 2.6 \mathrm{~mm}$ mediolateral, $-4.0 \mathrm{~mm}$ dorsoventral $\left(10^{\circ}\right.$ angle $)$. After cannulae implantation, rats received intravenous catheters and underwent recovery as described above. Rats then underwent heroin self-administration training as described above, followed by 1 or 14 withdrawal days. On withdrawal day 1 or 14 , rats received bilateral injections of either muscimol $(0.03 \mathrm{nmol} / 0.5 \mu \mathrm{l} /$ side $)+$ baclofen $(0.3 \mathrm{nmol} / 0.5 \mu \mathrm{l} /$ side $)$ (Tocris Bioscience) dissolved in sterile saline or its vehicle $5 \mathrm{~min}$ before the $90 \mathrm{~min}$ extinction test. Doses were based on previous studies (McFarland and Kalivas, 2001; Koya et al., 2009a; Bossert et al., 2011).

Intracranial injections were administered using a syringe pump (Harvard Apparatus) and $10 \mu \mathrm{l}$ Hamilton syringes attached via polyethylene-50 tubing to 30 gauge injectors (Plastics One). Baclofen + muscimol and its vehicle were injected over $1 \mathrm{~min}$, and the injectors were left in place for $1 \mathrm{~min}$. The number of rats per group included the following: vehicle day $1, n=7$; baclofen + muscimol day $14, n=9$; vehicle day $14, n=20$; and baclofen + muscimol day $14, n=12$ ).

To rule out the possibility that the effect of baclofen + muscimol on day 14 extinction responding (see Results) was attributable to motor deficits, seven rats were trained after completion of this experiment to lever press for $45 \mathrm{mg}$ food pellets (catalog \#1811155; Test Diet) under a fixed ratio 1 and $20 \mathrm{~s}$ timeout reinforcement schedule (Pickens et al., 2012) for 12 60-min sessions. Subsequently, we assessed the effect of vehicle or baclofen + muscimol injections into OFC on food-maintained responding in two different $60 \mathrm{~min}$ sessions separated by $48 \mathrm{~h}$. Test sessions were counterbalanced, and rats were run in food self-administration sessions on the day between the tests.

Experiment 4: effect of Daun02 inactivation of OFC activated neurons on cue-induced heroin seeking. We used the Daun02 inactivation procedure (Koya et al., 2009b) to determine a functional role of OFC neurons that were activated during the extinction tests. The mechanism of Daun02 inactivation is depicted in Figure $5 A$. This procedure uses $c$-fos-lac $Z$ transgenic rats that have a transgene containing a $c$-fos promoter that induces lac $Z$ transcription and the protein product $\beta$-galactosidase ( $\beta$ gal) in activated neurons similar to that for $c$-fos transcription and Fos protein from the endogenous $c$-fos gene (Kasof et al., 1995). $\beta$ gal metabolizes the prodrug Daun02 to its active form daunorubicin, which inactivates only the previously activated $\beta$ gal-expressing neurons (Farquhar et al., 2002).

Forty-two transgenic c-fos-lac $Z$ rats bred for 45-50 generations on a Sprague Dawley background were anesthetized and implanted with per- manent bilateral guide cannulae (23 gauge; Plastics One) aimed $1 \mathrm{~mm}$ above the OFC. Daun02 was dissolved in 5\% dimethylsulfoxide, $6 \%$ Tween 80 , and $89 \% 10$ mM PBS. Intracranial injections were administered as described above for baclofen + muscimol.

The experimental timeline is shown in Figure 4 A. Briefly, four groups of rats ( $n=8-13$ per group) were trained first to self-administer heroin. During the withdrawal phase, rats were removed from the selfadministration chambers and kept in new home cages in the animal facility for $11 \mathrm{~d}$. On induction day (day 11), half of the rats were exposed to the heroin-paired training context and cues during a short $15 \mathrm{~min}$ extinction session (termed heroin context) to induce $\beta$ gal, whereas the other half were exposed to a novel empty cage with clean bedding (termed novel context), and then all rats were returned to their home cages for $75 \mathrm{~min}$. Ninety minutes after the start of the extinction test, the rats were bilaterally injected with Daun02 $(2 \mu \mathrm{g} / 0.5 \mu \mathrm{l} /$ side $)$ or vehicle into the OFC and returned to their home cages. The Daun02 dose was based on our previous studies (Koya et al., 2009b; Bossert et al., 2011). Three days after the "induction" day, all rats underwent a 90 min drugfree extinction test as described above. At the end of the test session, the rats were anesthetized and perfused with paraformaldehyde as described above. Brains were removed for $\beta$ gal and Fos immunohistochemistry. Rats in the vehicle and Daun02 groups were matched for their heroin intake and number of active lever presses during training and induction day (induction day extinction session: vehicle, $71.5 \pm 21.3$ active lever presses/15 min; Daun02, $60.0 \pm 8.2 ; p=0.6$ ).

We used X-gal histochemistry to visualize $\beta$ gal as an indicator of neuronal activation. Thirty-micrometer free-floating sections were washed three times for $10 \mathrm{~min}$ each in PBS and incubated in reaction buffer (2.4 mM X-gal, $100 \mathrm{~mm}$ sodium phosphate, $100 \mathrm{~mm}$ sodium chloride, $5 \mathrm{~mm}$ EGTA, $2 \mathrm{mM} \mathrm{MgCl}_{2}, 0.2 \%$ Triton X-100, $5 \mathrm{~mm} \mathrm{~K}_{3} \mathrm{FeCN}_{6}$, and 5 $\mathrm{mMK}_{4} \mathrm{FeCN}_{6}$ ) for $4.5 \mathrm{~h}$ at $37^{\circ} \mathrm{C}$ with gentle shaking. Sections were washed three times for 10 min each in PBS, mounted onto chromalumgelatin-coated slides, and air dried. Slides were dehydrated through a graded series of ethanol $(30,60,90,95,100,100 \%$ ethanol), cleared with Citrasolv, and coverslipped with Permount. Bright-field images of OFC $\beta$ gal activity were captured using a Qimaging Exi Aqua camera attached to a Carl Zeiss Axioskop 2 microscope. Images for counting labeled cells were captured at $50 \times$ magnification. $\beta$ gal-expressing nuclei, characterized by blue nuclear staining, were counted using iVision MacOS 10.62 (version 4.0.15). We counted labeled nuclei in sampling areas $(\sim 1.09$ $\mathrm{mm}^{2}$ ) around the OFC injection site (left and right hemispheres) in two coronal sections per rat. Counts from all images from each rat were averaged, so that each rat was represented as a single observation in the statistical analyses and figures.

To assess coexpression, we double-labeled $\beta$ gal and Fos using fluorescent immunohistochemistry in four $c$-fos-lac $Z$ rats. Experimental procedures were similar to those described for Fos + NeuN labeling, with the exception that $30 \mu \mathrm{m}$ sections were used. Primary antibodies were rabbit anti-Fos primary antibody (1:500 dilution, sc-52; Santa Cruz Biotechnology) and goat anti- $\beta$ gal primary antibody (1:1000 dilution, 4600-1409; Biogenesis), and secondary antibodies were Alexa Fluor 488-labeled donkey anti-rabbit and Alexa Fluor 568-labeled donkey anti-goat (both 1:200 dilution).

Statistical analyses. The behavioral and molecular data were analyzed by ANOVAs using the statistical program SPSS (GLM procedure); significant effects $(p<0.05)$ were followed by Fisher's PLSD post hoc tests. The dependent measures and the factors used in the statistical analyses are described in Results. Inactive lever responding, a potential measure of nonspecific activity and/or response generalization (Shalev et al., 2002), was used as a covariate in the statistical analysis, and the data for this measure are described in Table 1.

\section{Results}

The rats demonstrated reliable heroin self-administration in all experiments (Fig. $1 A$, final total $n=141$ ). ANOVA indicated a main effect of training session $\left(F_{(1,117)}=23.7, p<0.01\right)$ but not experiment $(p>0.05)$. Mean \pm SEM 10-day daily heroin intake (infusions per $6 \mathrm{~h}$ ) was $30.0 \pm 2.8,26.0 \pm 4.5,28.0 \pm 1.8$, and 
Table 1. Mean \pm SEM of inactive lever presses in experiments 1-4

\begin{tabular}{|c|c|c|c|}
\hline Experiment 1 & Experiment 2 & Experiment 3 & Experiment 4 \\
\hline Day $1: 1.8 \pm 1.0$ & $6.9 \pm 0.6$ & Day 1 vehicle: $3.0 \pm 2.2$ & Novel context + vehicle: $29 \pm 8.5$ \\
\hline \multirow[t]{3}{*}{ Day $14: 5.9 \pm 1.7$} & & Day 1 baclofen + muscimol: $1.0 \pm 0.5$ & Novel context + Daun02: $39 \pm 15.1$ \\
\hline & & Day 14 vehicle: $12.0 \pm 2.7$ & Heroin context + vehicle: $22 \pm 5.7$ \\
\hline & & Day 14 baclofen + muscimol: $8.0 \pm 2.2$ & Heroin context + Daun02: $30 \pm 6.0$ \\
\hline
\end{tabular}
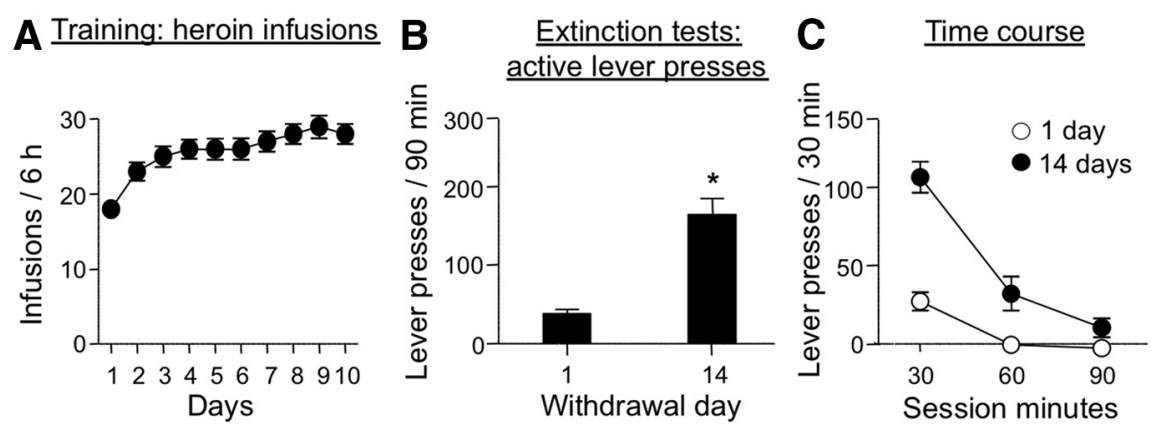

Figure 1. Rats reliably self-administer heroin and demonstrate time-dependent increases in cue-induced heroin seeking in the extinction tests after withdrawal (incubation of heroin craving). $\boldsymbol{A}$, Rats were trained to self-administer heroin over $10 \mathrm{~d}$. Data are pooled across experiments $1-4$ and represent mean \pm SEM heroin infusions per day (total $n=141)$. $\boldsymbol{B}, \boldsymbol{C}$, Cue-induced heroin seeking after 1 or 14 withdrawal days ( $n=9-13$ per group). During the extinction tests, active lever presses resulted in delivery of a light cue paired previously with heroin infusions but not heroin. Data are mean \pm SEM active lever presses from experiment $1 ;{ }^{*} p<0.05$, different from day 1.

$27.0 \pm 2.3$ for experiments $1(n=44), 2(n=7), 3(n=48)$, and $4(n=42)$, respectively. From all experiments, 29 rats were excluded: four for inadequate training ( $<10$ infusions/d), 24 for misplaced cannulae (experiments 3 and 4 ; rostral to $+4.5 \mathrm{~mm}$ or caudal to $+2.5 \mathrm{~mm}$ from bregma; see also additional text below for experiment 3 ), and one because lever presses in the extinction test were $>2$ SDs from the group mean (experiment 3 ).

\section{Cue-induced heroin seeking and OFC neuronal activation} after withdrawal from heroin

Extinction tests

Cue-induced heroin seeking (operationally defined as the number of non-reinforced responses on the previously active lever during extinction tests) was significantly higher after 14 withdrawal days ( $n=$ 9) than after $1 \mathrm{~d}(n=13$; Fig. $1 B)$, confirming previous reports on incubation of heroin craving (Shalev et al., 2001; Kuntz et al., 2008a; Airavaara et al., 2011). The ANOVA of total responding (90 $\mathrm{min}$ ) on the active lever, which included the between-subjects factor of withdrawal day and the covariate of inactive lever responding, demonstrated a significant effect of withdrawal day $\left(F_{(1,19)}=31.9, p<\right.$ 0.01 ). Time course (in 30 min intervals) of active lever presses during the extinction tests on withdrawal days 1 and 14 is shown in Figure $1 C$.

Fos

Exposure to the heroin context and cues during the extinction tests increased Fos expression in OFC, an effect that was somewhat more pronounced after 14 withdrawal days than after $1 \mathrm{~d}$ (Fig. 2A). The ANOVA, which included the between-subjects factors of group (day 1 extinction test, day 1 no test, day 14 extinction test, and day 14 no test), demonstrated a main effect of group $\left(F_{(1,39)}=5.0, p<0.01\right)$. Post hoc analysis (Fisher's PLSD test) indicated that Fos immunoreactivity was significantly increased in the extinction test group versus the no-test group on withdrawal day $14(n=10 ; p<0.05)$ but not day $1(n=12$; $p>0.05)$.

\section{heroin seeking after prolonged}

\section{Characterization of OFC activated neurons on withdrawal day 14}

We used double-labeling immunohistochemistry to further characterize the OFC neurons in seven rats that were trained to self-administer heroin for $10 \mathrm{~d}$ and given a 90 min extinction test after 14 withdrawal days (mean \pm SEM of active and inactive lever responding during the test was $130.0 \pm 38.0$ and $7.0 \pm 0.06$, respectively). Using NeuN and Fos colocalization, we found that $12.1 \pm 1.4 \%$ of all OFC neurons in the sections were activated during the extinction test (Fig. 2C--E). Of these activated neurons, $55.2 \pm 6.7 \%$ was colocalized with CaMKII and 10.2 \pm 4.9\% with GAD67.

\section{Reversible inactivation of the majority} of OFC neurons decreased cue-induced

\section{but not early withdrawal}

Injections of baclofen + muscimol into the OFC just before the extinction tests on withdrawal day 14 but not day 1 decreased cue-induced heroin seeking in these tests (Fig. $3 A, B$ ). The ANOVA of total ( $90 \mathrm{~min}$ ) active lever presses, which included the between-subjects factors of drug condition (baclofen + muscimol, vehicle) and withdrawal day, and the covariate of inactive lever responding demonstrated a significant main effect of withdrawal day $\left(F_{(1,43)}=15.0, p<0.01\right)$. Initial analysis did not reveal a main effect of drug condition $(p>0.05)$ or an interaction between withdrawal day and drug condition $(p>0.05)$ but subsequent one-way ANOVA across the four groups (day 1 vehicle, $n=7$; day 14 vehicle, $n=20$; day 1 baclofen + muscimol, $n=9$; day 14 baclofen + muscimol, $n=12$ ) demonstrated a significant effect of group $\left(F_{(3,43)}=7.3, p<0.01\right.$; covariate of inactive lever responding). Post hoc analyses demonstrated significant differences between day 14 vehicle group versus day 1 vehicle $(p<0.01)$ and day 14 baclofen + muscimol $(p<0.05)$ groups. Time course of active lever presses in 30 min blocks is shown in Figure $3 B$.

Histological analysis indicated that baclofen + muscimol injections had no effect on extinction responding after 14 withdrawal days if the injector tip was located exclusively within the ventral OFC (medial to $\pm 2.2 \mathrm{~mm}$ from the midline). Thus, cases in which injector tips were located in the ventral OFC $(n=4)$ were not included in the baclofen + muscimol analysis; mean \pm SEM of active lever presses during the 90 min extinction test for these rats was $153.0 \pm 36.0$, which was higher than the mean of the day 14 vehicle group described in Figure $3(108.0 \pm 14.0)$. Five additional rats were excluded, because one injector was placed in the lateral OFC and another in the ventral OFC; the mean \pm SEM of active lever press during the 90 min extinction test for these rats was $74.0 \pm 45.0$, which was similar to the mean for the day 14 baclofen + muscimol group described in Figure 3 
A

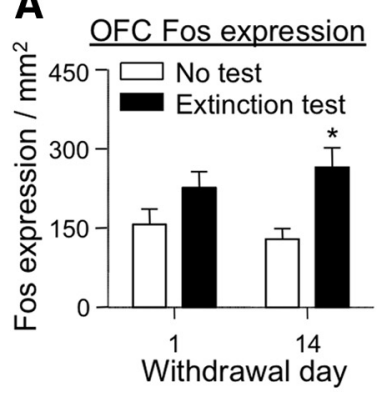

Fos+NeuN labeling

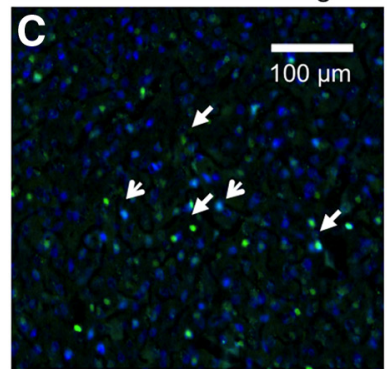

$12.1 \%$ of NeuN-positive neurons were Fos-positive
B
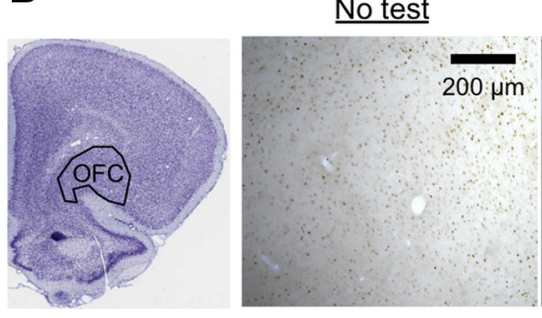

Extinction test

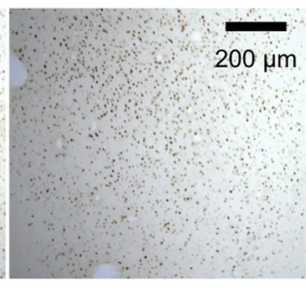

Fos+CamKII labeling

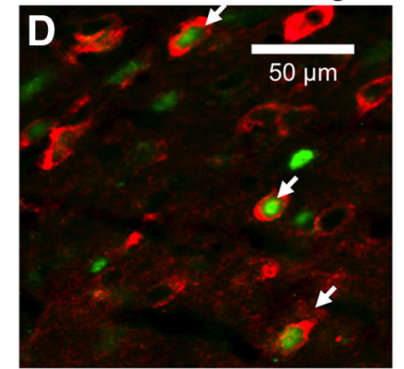

$55.2 \%$ of Fos-positive neurons were CamKII-positive

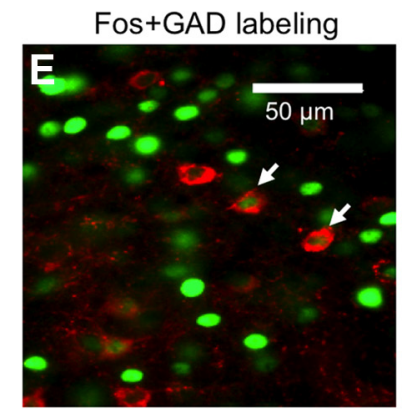

$10.2 \%$ of Fos-positive neurons were GAD-positive

Figure 2. Effect of cue-induced heroin seeking on OFC Fos expression and characterization of activated OFC neurons. All rats were trained to self-administer heroin for $10 \mathrm{~d}$, followed by 14 withdrawal days; rats were then tested (Extinction test) or not tested (No test) for cue-induced heroin seeking. $A$, Fos expression in OFC in extinction test versus no-test rats; ${ }^{*} p<0.01$, different from the no-test group; $n=9-13$ per experimental condition. $\boldsymbol{B}$, Representative OFC images for extinction test and no-test rats on day 14 . Scale bar, $200 \mu \mathrm{m}$. C $\boldsymbol{E}$, Characterization of Fos-expressing neurons in OFC of extinction test rats after 14 withdrawal days. C, Fos + NeuN double labeling in OFC. Scale bar, $100 \mu \mathrm{m}$. NeuN labeling in blue, Fos labeling in green, and double-labeled neurons in blue and green (indicated by white arrows). D, Fos + CaMKII double labeling in OFC. Scale bar, $50 \mu \mathrm{m}$. CaMKII labeling in red, Fos labeling in green, and double-labeled neurons in red and green (indicated by white arrows).E, Fos + GAD67 double labeling in OFC. Scale bar, $50 \mu \mathrm{m}$. GAD67 labeling in red, Fos labeling in green, and double-labeled neurons in red and green (indicated by white arrow).

$(69.0 \pm 14.0)$. Because extinction responding was not affected by cannula placement medial to $\pm 2.2 \mathrm{~mm}$ in the day 14 vehicle group, rats in the vehicle groups who had at least one cannula lateral to $\pm 2.2 \mathrm{~mm}$ were included in the behavioral analyses $(n=5$ of 20 rats in the day 14 vehicle group).

Baclofen + muscimol OFC injections had no effect on high-rate food-reinforced responding: mean \pm SEM number of active lever presses per $60 \mathrm{~min}$ was $166.0 \pm 36.0$ after vehicle injections and $180.0 \pm 44.0$ after baclofen + muscimol injections $(p>$ 0.1 ). These data indicate that the effects of OFC baclofen + muscimol injections on cue-induced heroin seeking in the extinction test on withdrawal day 14 are not attributable to motor deficits.

\section{Selective inactivation OFC neuronal ensembles decreased cue-induced heroin seeking}

Based on our anatomical results above with baclofen + muscimol, we injected Daun02 and vehicle into the lateral OFC. Injections of Daun02 on induction day, 3 $\mathrm{d}$ before the withdrawal day 14 extinction test, decreased enhanced cue-induced heroin seeking (or the expression of incubation of heroin craving) and $\beta$ gal expression
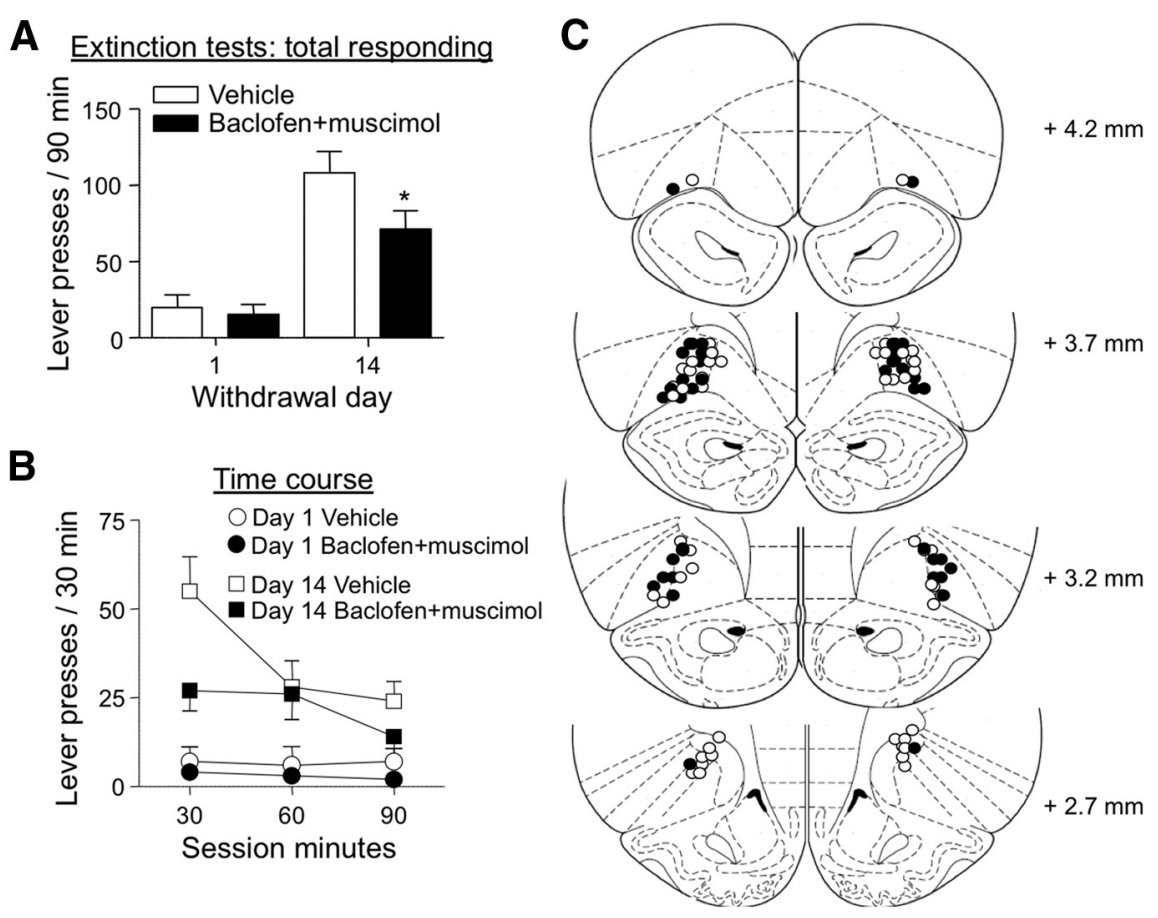

Figure 3. Lateral OFC baclofen + muscimol injections decreased incubated cue-induced heroin seeking after 14 withdrawal days. $\boldsymbol{A}$, Total lever responding during $90 \mathrm{~min}$ extinction test. Baclofen + muscimol $(0.3 \mathrm{nmol}$ and $0.03 \mathrm{nmol} / 0.5 \mu \mathrm{l} / \mathrm{side})$ or vehicle was injected into the lateral OFC 5-10 min before 90 min extinction tests after 1 or 14 withdrawal days $(n=7-20$ per experimental condition). $\boldsymbol{B}$, Time course of active lever presses in 30 min bins. $\boldsymbol{C}$, Cannulae placement: approximate placement of injector tips (Paxinos and Watson, 2005); white and black dots indicate locations of vehicle and baclofen + muscimol injections, respectively. ${ }^{*} p<0.05$, different from vehicle. 

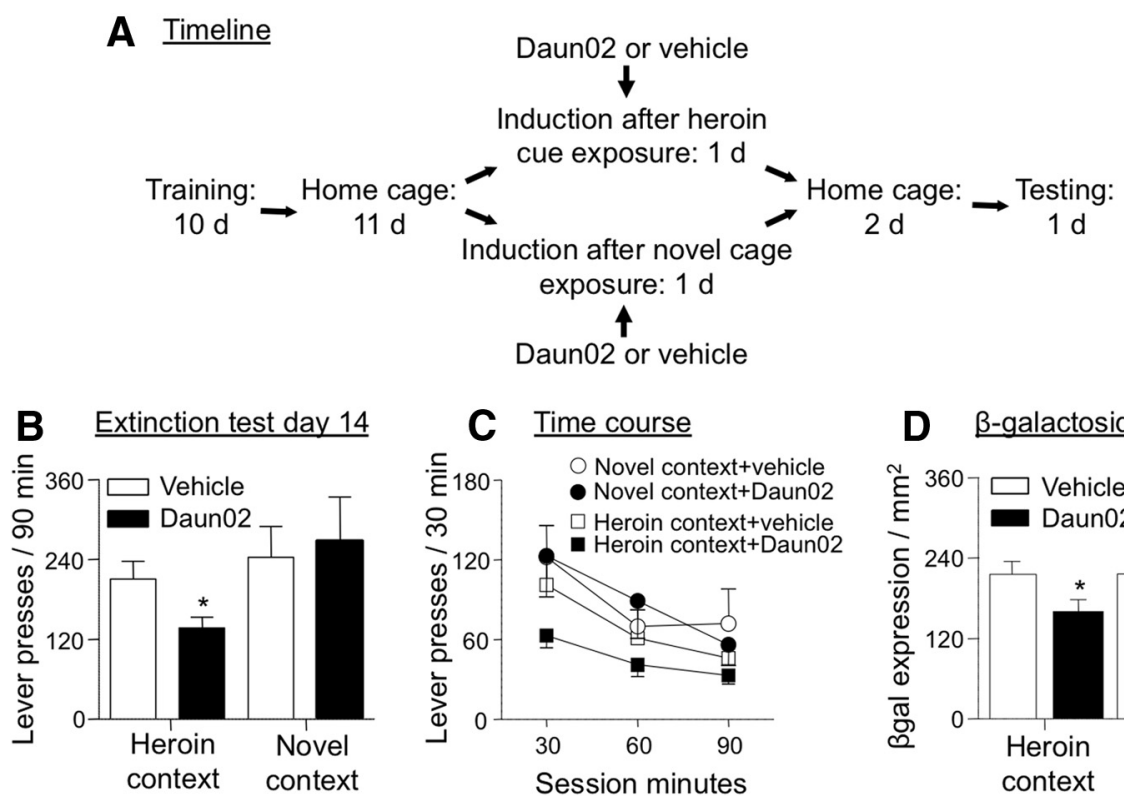

\section{D $\underline{\text {-galactosidase }}$}

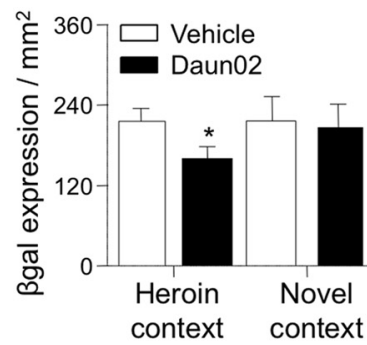

E

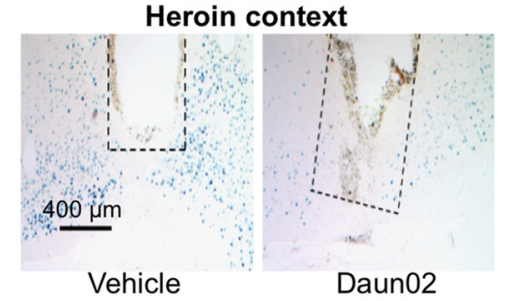

Novel context

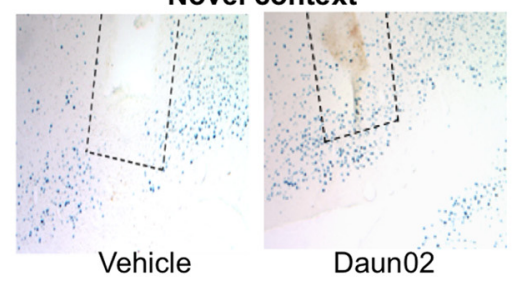

$\mathbf{F}$

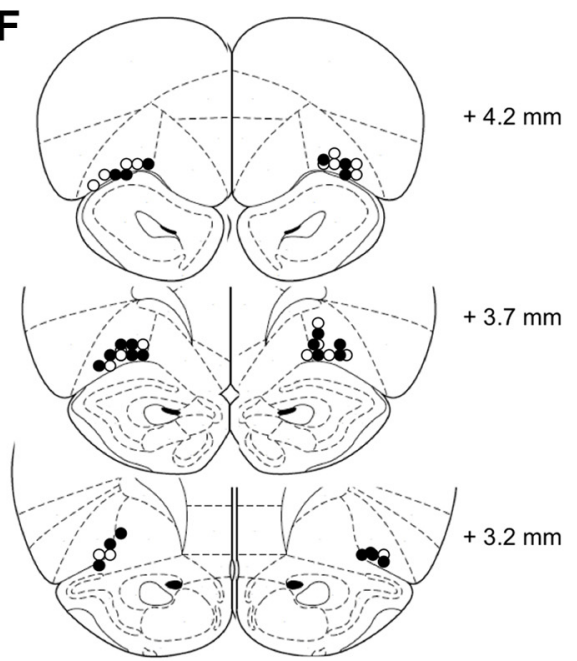

Figure 4. OFC Daun02 injections after exposure to the heroin cues in a short extinction test during induction day decreased subsequent incubated cue-induced heroin seeking and neuronal activation. $\boldsymbol{A}$, Timeline of experimental procedure: during induction day, Daun02 $(2 \mu \mathrm{g} / \mathrm{side})$ or vehicle was injected into the $0 \mathrm{FC} 90 \mathrm{~min}$ after a short 15 min exposure to heroin cues in an extinction session or a novel context. $B, C$, Daun02 injections after exposure to the heroin cues during a short extinction session, but not to a novel environment, on induction day reduced cue-induced heroin seeking (active lever presses) and heroin cue-induced activation of OFC neurons ( $\beta$ gal expression) 3 days later (D) $(n=8-13$ per group). Data are mean \pm SEM total active lever presses. $\boldsymbol{E}$, Images depict $\beta$ gal-labeled nuclei in OFC for each behavioral group; dotted lines indicate approximate area of injector tip. Scale bar, $400 \mu \mathrm{m}$. F, Cannulae placement: approximate placement of injector tips; white and black dots indicate locations of vehicle and Daun02 injections, respectively. ${ }^{*} p<0.05$, different from vehicle.

when Daun02 was injected after brief exposure to a short extinction session (15 $\mathrm{min})$ in the heroin self-administration context but not when Daun02 was injected after exposure to a novel context (Fig. $4 B, C)$. We used a short 15 min extinction session on induction day to activate neurons sufficiently to induce $\beta$ gal while minimizing a carryover effect of extinction responding from induction day (day 11) to day 14 extinction test. We kept the rats for an additional 75 min in clean home cages to ensure sufficient production of $\beta$ gal in the Fos-activated neurons.

\section{Extinction test}

Because the novel context and heroin context groups had different extinction experiences before the 90 min extinction test on withdrawal day 14 [no extinction experience in the novel context vs brief ( $15 \mathrm{~min}$ ) extinction experience in the heroin chambers on induction day], extinction test data from these groups were ana- lyzed separately. The ANOVA of total (90 min) active lever presses for the novel context groups ( $n=9$, vehicle; $n=8$, Daun02), which included the between-subjects factor of drug condition (Daun02, vehicle) and the covariate of inactive lever responding, indicated no significant group difference $(p>0.1)$. The ANOVA of total (90 $\mathrm{min}$ ) active lever presses for the heroin context groups ( $n=12$, vehicle; $n=13$, Daun02), which included the between-subjects factors of drug condition (Daun02, vehicle) and the covariates of inactive lever test responding and active lever responses on induction day, indicated a significant effect of drug condition $\left(F_{(1,25)}=6.8, p<0.05\right)$. Time course of active lever responding in $30 \mathrm{~min}$ blocks is shown in Figure $4 C$.

Bgal labeling

The ANOVA, which included the between-subjects factor of group (heroin context + vehicle, heroin context + Daun02, 
A

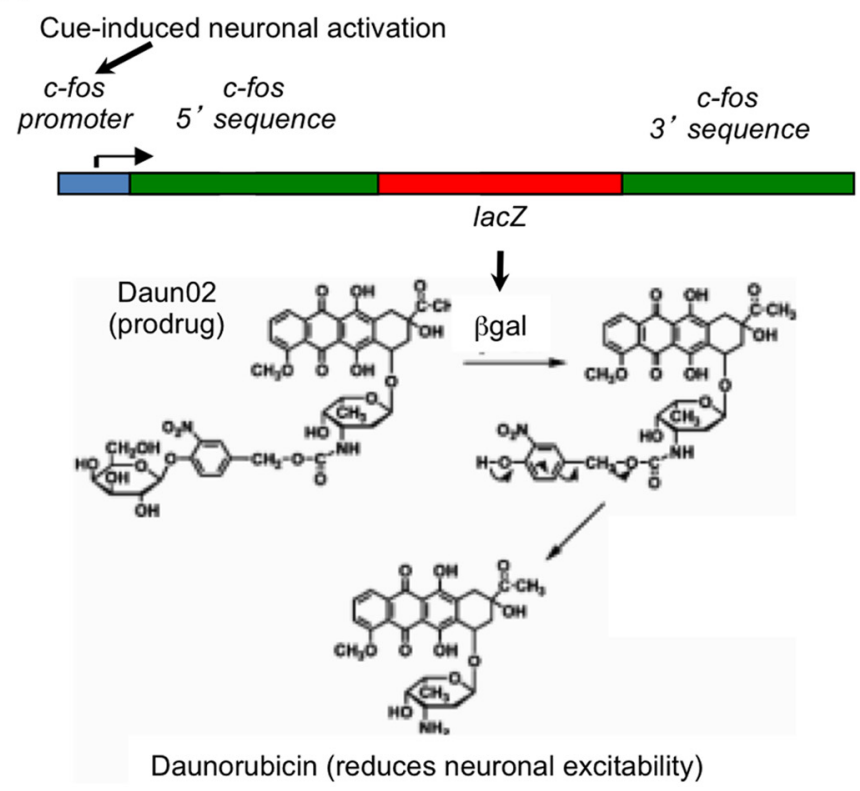

B

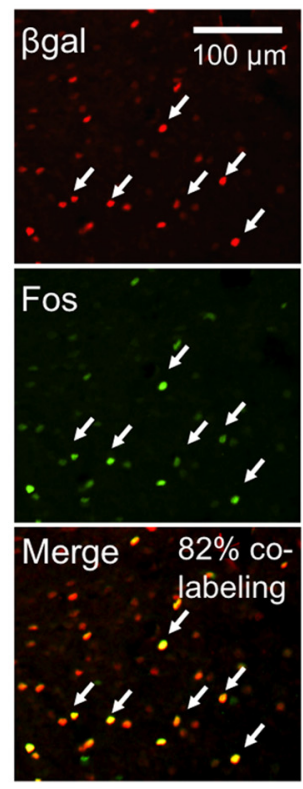

Figure 5. Daun02 mechanism and colocalization with Fos. A, Schematic mechanism for Daun02 inactivation in c-fos-lacZ rats (adapted from Koya et al., 2009b). The c-fos-lacZ transgene contains a c-fos promoter that drives transcription of lac $Z$ that encodes the bacterial protein $\beta$ gal. $\beta$ gal catalyzes conversion of the prodrug Daun02 into daunorubicin, which decreases cellular excitability. $\boldsymbol{B}$, Double labeling of $\beta$ gal and Fos in OFC; $\beta$ gal labeling in red, Fos labeling in green, and double-labeled neurons in red and green (indicated by white arrows). Scale bar, $400 \mu \mathrm{m}$.

novel context + vehicle, novel context + Daun02), demonstrated a significant effect of group $\left(F_{(3,37)}=3.5, p<0.05\right.$; Fig. $4 D)$. Post hoc analysis (Fisher's PLSD test) indicated that $\beta$ gal labeling was significantly lower in the heroin context + Daun02 group than in the other three groups ( $p$ values $<0.05$ ).

Finally, we quantified the degree of colabeling for $\beta$ gal and Fos. We found that $82 \pm 1 \%$ of $\beta$ gal-expressing neurons in OFC were also Fos labeled (Fig. 5B). This value is similar to what has been observed previously in the mPFC (Bossert et al., 2011).

\section{Discussion}

We studied the role of cue-activated OFC neuronal ensembles in the expression of incubation of heroin craving after withdrawal. Cue-induced heroin seeking in the extinction tests was higher after 14 withdrawal days than after $1 \mathrm{~d}$, confirming previous reports on incubation of heroin craving (Shalev et al., 2001; Kuntz et al., 2008a). Cue-induced heroin seeking also increased Fos expression on withdrawal day 14 (but not day 1), similar to previous reports (Koya et al., 2006; Kuntz et al., 2008b). Doublelabeled immunohistochemistry indicated that these Fos-positive neurons were both glutamatergic and GABAergic neurons and comprised $\sim 12 \%$ of all OFC neurons in a $30-\mu$ m-thick slice, which translates to $\sim 4 \%$ in a three-dimensional volume. General inactivation of the majority of neurons in the lateral OFC with baclofen + muscimol decreased incubated cue-induced heroin seeking on withdrawal day 14 but had no effect on non-incubated responding on day 1 . Selective inactivation of only the Fos- and $\beta$ gal-positive neurons that were activated previously during cueinduced heroin seeking decreased subsequent heroin seeking on withdrawal day 14. Based on these data, we suggest that OFC neuronal ensembles encode learned associations between environmental cues and heroin effects that contribute to the expression of incubation of cue-induced heroin craving after withdrawal.

Neuronal ensembles have been traditionally studied with in vivo electrophysiology using multielectrode recordings, which provide temporal information on neuronal activity patterns (i.e., "when" the neurons are activated during behavior) (Eichenbaum, 1993; Pennartz et al., 1994) or with histochemical detection of immediate-early genes such as $c$-fos or arc that provide information about the spatial expression patterns of neurons activated during behavior (i.e., "where" the neuronal ensembles are in the brain) (Guzowski et al., 1999, 2001). However, data from studies using these methods are correlational and do not establish causal roles of the activated neurons in behavior.

We developed the Daun02 inactivation procedure to study causal roles of putative neuronal ensembles in conditioned drug effects and relapse (Koya et al., 2009b). With this method, selective inactivation of behaviorally activated neurons is performed by injecting the prodrug Daun02 into specific brain areas of $c$-foslac $Z$ transgenic rats (Kasof et al., 1996) that express $\beta$ gal (the lac $Z$ gene protein product) in neurons strongly activated during behavior (Koya et al., 2009b). $\beta$ gal within the behaviorally activated neurons converts Daun02 into daunorubicin, which disrupts the normal function of these neurons (Koya et al., 2009b). We used the Daun02 procedure in two previous studies to demonstrate causal roles of putative neuronal ensembles in nucleus accumbens and ventral mPFC in context-specific locomotor sensitization (Koya et al., 2009b) and context-induced reinstatement of heroin seeking (Bossert et al., 2011).

In the current study, we found that cue-induced heroin seeking on test day was attenuated by previous Daun02 inactivation of only OFC neurons that were selectively activated by heroin cues and drug seeking to induce Fos and $\beta$ gal on induction day (Fig. $4 B-D)$. An unlikely interpretation of our data is that Daun02 injections on induction day decreased cue-induced heroin seeking during testing $3 \mathrm{~d}$ later by nonspecifically inactivating neurons regardless of their activation state or by inactivating a random set of Fos-activated neurons. We previously demonstrated that Daun02 injections had no effect on context- 
dependent cocaine psychomotor sensitization or contextinduced reinstatement of heroin seeking when injections were made after exposure to alternate environments associated with saline injections or extinction training (Koya et al., 2009b; Bossert et al., 2011). In the current study, Daun02 did not attenuate subsequent cue-induced heroin seeking when infused into OFC of rats exposed to a novel context on induction day; it is well established that novel context exposure causes strong Fos induction in cortical areas (Badiani et al., 1998; Badiani and Robinson, 2004; Paolone et al., 2007). Based on these data, we postulate that specific heroin-cue-activated neuronal ensembles in OFC mediate at least part of the learned associations between heroin effect and the environment of drug intake, which drives heroin seeking after prolonged abstinence.

One methodological consideration in our study is the anatomical specificity of baclofen + muscimol or Daun02 injections into the lateral OFC. At issue here is that drugs injected into specific brain sites can change behavior by diffusing away from the injection site into nearby sites (Wise and Hoffman, 1992). We cannot rule out a potential role of the nearby claustrum or the anterior insular cortex. However, our results demonstrate an anatomical-specific effect for the lateral versus ventral OFC, because ventral OFC baclofen + muscimol injections were ineffective (see Results). This pattern of results is similar to that of Fuchs et al. (2004) who reported that lateral but not ventral (termed medial in the authors' paper) OFC inactivation decreased cueinduced reinstatement of cocaine seeking. Future experiments are necessary to demonstrate conclusively that baclofen + muscimol inactivation of ventral OFC has no effect on heroin seeking under our experimental conditions. Finally, baclofen + muscimol or Daun02 inactivation of the lateral OFC only partially attenuated heroin-seeking behavior on test day $(\sim 35 \%)$. These data suggest that other brain areas also contribute to the expression of incubation of heroin craving.

\section{Theoretical considerations}

One issue within the neuronal ensemble framework is that we do not know what specific component of heroin-seeking behavior was disrupted by Daun02 inactivation of OFC neuronal ensembles. Lever presses during the short extinction sessions on induction day (Fig. 4) are controlled by distinct learning processes that are likely encoded by different neuronal ensembles: these different learning processes include operant responding previously reinforced by heroin, the conditioned reinforcing effects of the discrete cue previously paired with heroin injections (Feltenstein and See, 2008), and reexposure to contextual cues in the chambers that induce drug seeking (Crombag et al., 2008). Different neural circuitry has been shown to mediate contextual cue versus discrete cue-induced drug seeking (Bossert et al., 2007; Crombag et al., 2008). Future experiments are required to dissect which components of heroin seeking are mediated by OFC neuronal ensembles in our study.

Another issue is whether the OFC plays a unique role in incubation of cue-induced heroin craving versus a more general role in cue-induced drug seeking independent of the withdrawal period. Support for a unique role in incubation is the pattern of results for the Fos data (significant extinction test effect on withdrawal day 14 but not day 1; Fig. 2) and the baclofen + muscimol data (significant drug effect on extinction responding on withdrawal day 14 but not day 1; Fig. 3). However, we cannot rule out the latter possibility-a general role of lateral OFC in cueinduced drug seeking - because we did not observe statistically significant interactions of withdrawal day $\times$ extinction test con- dition (test, no test) for Fos induction or withdrawal day $\times$ drug condition (baclofen + muscimol, vehicle) for lever presses (data not shown). Additionally, the nonsignificant effect of baclofen + muscimol on day 1 may reflect a floor effect attributable to low responding.

Finally, we do not know which OFC-dependent psychological processes are disrupted by baclofen + muscimol or Daun02 inactivation to attenuate cue-induced heroin seeking. Imaging studies showed that cue-induced OFC activation correlates with subjective craving (Sell et al., 1999, 2000; Langleben et al., 2008), which supports the idea that lateral OFC neuronal ensembles in our study encode cue-induced motivational effects that promote drug seeking. This idea is consistent with evidence that OFC neurons respond to motivationally significant cues to mediate outcome-guided behavior (Schoenbaum and Eichenbaum, 1995; Gallagher et al., 1999; Noonan et al., 2010). Because the OFC has been implicated in behaviors reflecting current values of reward outcomes (Schoenbaum et al., 2009), the involvement of OFC here suggests that incubation of heroin craving could reflect a time-dependent growth of the current value of heroin.

Drug exposure also produces general impairments of OFCdependent psychological processes (Lucantonio et al., 2012). Such impairments have been suggested to underlie impulsive decision-making and compulsive drug use despite adverse consequences (Jentsch and Taylor, 1999; Volkow and Fowler, 2000; Schoenbaum and Shaham, 2008). Cocaine exposure mimics the deleterious effects of OFC lesions on reversal learning (Jentsch et al., 2002; Schoenbaum et al., 2004) and pavlovian overexpectation (Lucantonio et al., 2012). These learning deficits, however, do not seem to underlie the current findings, because Daun02 or baclofen + muscimol decreased cue-induced heroin seeking at the beginning of the extinction test session before any opportunity for impaired learning to occur. Furthermore, evidence for OFC-dependent aberrant learning processes in addiction comes primarily from studies using psychostimulants (Jentsch and Taylor, 1999; Lucantonio et al., 2012), which often have different effects on brain function than opiates (Badiani et al., 2011). Indeed, morphine self-administration had no effect on pavlovian over-expectation (F. Lucantonio and G. Schoenbaum, unpublished observations), an OFCdependent task impaired by cocaine exposure (Lucantonio et al., 2012).

\section{Concluding remarks}

We used classical behavioral, immunohistochemistry, and reversible inactivation procedures in combination with the pharmacogenetic Daun02-selective inactivation procedure to demonstrate a role of putative OFC neuronal ensembles in cueinduced heroin seeking after withdrawal. The present study and previous studies (Koya et al., 2009b; Bossert et al., 2011) are consistent with the "cell assembly" hypothesis proposed by Hebb (1949) that specific patterns of neurons activated by external and internal cues during learning form neuronal ensembles that encode and control learned behaviors. Similar $c$-fos or CREB promoter-based procedures have been used recently to demonstrate causal roles of neuronal ensembles in conditioned fear using transgenic mice (Han et al., 2009; Garner et al., 2012; Liu et al., 2012). In these studies, Fos-expressing neurons had to have high integrated levels of activity during the first 15-30 min of exposure to environmental cues to induce Fos. Thus, average levels of activation of these neurons had to have been synchronized over this 15-30 min period, which may be necessary for psychological processes that persist over these timescales. Schoenbaum, 
Setlow, and colleagues have documented correlations between OFC neuronal activity and behavior using in vivo electrophysiology (Schoenbaum and Setlow, 2001; Schoenbaum et al., 2003). Future studies will have to examine the relationships between these electrophysiology data and activated Fos and $\beta$ gal-expressing neurons in our study and whether the activated neurons demonstrate unique drug-induced synaptic alterations that are different from the majority of the surrounding non-activated neurons. Finally, our data extend recent reports on the important role of different subregions of the prefrontal cortex in relapse to heroin seeking (LaLumiere and Kalivas, 2008; Rogers et al., 2008; Van den Oever et al., 2008, 2010; Bossert et al., 2012).

\section{References}

Abdolahi A, Acosta G, Breslin FJ, Hemby SE, Lynch WJ (2010) Incubation of nicotine seeking is associated with enhanced protein kinase A-regulated signaling of dopamine- and cAMP-regulated phosphoprotein of $32 \mathrm{kDa}$ in the insular cortex. Eur J Neurosci 31:733-741.

Airavaara M, Pickens CL, Stern AL, Wihbey KA, Harvey BK, Bossert JM, Liu QR, Hoffer BJ, Shaham Y (2011) Endogenous GDNF in ventral tegmental area and nucleus accumbens does not play a role in the incubation of heroin craving. Addict Biol 16:261-272.

Badiani A, Robinson TE (2004) Drug-induced neurobehavioral plasticity: the role of environmental context. Behav Pharmacol 15:327-339.

Badiani A, Oates MM, Day HE, Watson SJ, Akil H, Robinson TE (1998) Amphetamine-induced behavior, dopamine release, and c-fos mRNA expression: modulation by environmental novelty. J Neurosci 18:10579-10593.

Badiani A, Belin D, Epstein D, Calu D, Shaham Y (2011) Opiate versus psychostimulant addiction: the differences do matter. Nat Rev Neurosci 12:685-700.

Bienkowski P, Rogowski A, Korkosz A, Mierzejewski P, Radwanska K, Kaczmarek L, Bogucka-Bonikowska A, Kostowski W (2004) Timedependent changes in alcohol-seeking behaviour during abstinence. Eur Neuropsychopharmacol 14:355-360.

Bossert JM, Poles GC, Wihbey KA, Koya E, Shaham Y (2007) Differential effects of blockade of dopamine $\mathrm{D}_{1}$-family receptors in nucleus accumbens core or shell on reinstatement of heroin seeking induced by contextual and discrete cues. J Neurosci 27:12655-12663.

Bossert JM, Wihbey KA, Pickens CL, Nair SG, Shaham Y (2009) Role of dopamine $\mathrm{D}(1)$-family receptors in dorsolateral striatum in contextinduced reinstatement of heroin seeking in rats. Psychopharmacology (Berl) 206:51-60.

Bossert JM, Stern AL, Theberge FR, Cifani C, Koya E, Hope BT, Shaham Y (2011) Ventral medial prefrontal cortex neuronal ensembles mediate context-induced relapse to heroin. Nat Neurosci 14:420-422.

Bossert JM, Stern AL, Theberge FR, Marchant NJ, Wang HL, Morales M, Shaham Y (2012) Role of projections from ventral medial prefrontal cortex to nucleus accumbens shell in context-induced reinstatement of heroin seeking. J Neurosci 32:4982-4991.

Crombag HS, Bossert JM, Koya E, Shaham Y (2008) Context-induced relapse to drug seeking: a review. Philos Trans R Soc Lond B Biol Sci 363:3233-3243.

Eichenbaum H (1993) Thinking about brain cell assemblies. Science 261:993-994.

Farquhar D, Pan BF, Sakurai M, Ghosh A, Mullen CA, Nelson JA (2002) Suicide gene therapy using E. coli beta-galactosidase. Cancer Chemother Pharmacol 50:65-70.

Feltenstein MW, See RE (2008) The neurocircuitry of addiction: an overview. Br J Pharmacol 154:261-274.

Fuchs RA, Evans KA, Parker MP, See RE (2004) Differential involvement of orbitofrontal cortex subregions in conditioned cue-induced and cocaineprimed reinstatement of cocaine seeking in rats. J Neurosci 24:6600-6610.

Gallagher M, McMahan RW, Schoenbaum G (1999) Orbitofrontal cortex and representation of incentive value in associative learning. J Neurosci 19:6610-6614.

Garner AR, Rowland DC, Hwang SY, Baumgaertel K, Roth BL, Kentros C, Mayford M (2012) Generation of a synthetic memory trace. Science 335:1513-1516.
Grimm JW, Hope BT, Wise RA, Shaham Y (2001) Neuroadaptation. Incubation of cocaine craving after withdrawal. Nature 412:141-142.

Guzowski JF, McNaughton BL, Barnes CA, Worley PF (1999) Environmentspecific expression of the immediate-early gene Arc in hippocampal neuronal ensembles. Nat Neurosci 2:1120-1124.

Guzowski JF, McNaughton BL, Barnes CA, Worley PF (2001) Imaging neural activity with temporal and cellular resolution using FISH. Curr Opin Neurobiol 11:579-584.

Han JH, Kushner SA, Yiu AP, Hsiang HL, Buch T, Waisman A, Bontempi B, Neve RL, Frankland PW, Josselyn SA (2009) Selective erasure of a fear memory. Science 323:1492-1496.

Hebb DO (1949) The organization of behavior. New York: Wiley.

Jentsch JD, Taylor JR (1999) Impulsivity resulting from frontostriatal dysfunction in drug abuse: implications for the control of behavior by reward-related stimuli. Psychopharmacology 146:373-390.

Jentsch JD, Olausson P, De La Garza R 2nd, Taylor JR (2002) Impairments of reversal learning and response perseveration after repeated, intermittent cocaine administrations to monkeys. Neuropsychopharmacology 26:183-190

Kasof GM, Mandelzys A, Maika SD, Hammer RE, Curran T, Morgan JI (1995) Kainic acid-induced neuronal death is associated with DNA damage and a unique immediate-early gene response in c-fos-lacZ transgenic rats. J Neurosci 15:4238-4249.

Kasof GM, Smeyne RJ, Curran T, Morgan JI (1996) Developmental expression of Fos-lacZ in the brains of postnatal transgenic rats. Brain Res Dev Brain Res 93:191-197.

Kaufman DL, McGinnis JF, Krieger NR, Tobin AJ (1986) Brain glutamate decarboxylase cloned in lambda gt-11: fusion protein produces gammaaminobutyric acid. Science 232:1138-1140.

Kaufman DL, Houser CR, Tobin AJ (1991) Two forms of the gammaaminobutyric acid synthetic enzyme glutamate decarboxylase have distinct intraneuronal distributions and cofactor interactions. J Neurochem 56:720-723.

Koya E, Spijker S, Voorn P, Binnekade R, Schmidt ED, Schoffelmeer AN, De Vries TJ, Smit AB (2006) Enhanced cortical and accumbal molecular reactivity associated with conditioned heroin, but not sucrose-seeking behaviour. J Neurochem 98:905-915.

Koya E, Uejima JL, Wihbey KA, Bossert JM, Hope BT, Shaham Y (2009a) Role of ventral medial prefrontal cortex in incubation of cocaine craving. Neuropharmacology 56 [Suppl 1]:177-185.

Koya E, Golden SA, Harvey BK, Guez-Barber DH, Berkow A, Simmons DE, Bossert JM, Nair SG, Uejima JL, Marin MT, Mitchell TB, Farquhar D, Ghosh SC, Mattson BJ, Hope BT (2009b) Targeted disruption of cocaine-activated nucleus accumbens neurons prevents context-specific sensitization. Nat Neurosci 12:1069-1073.

Kuntz KL, Twining RC, Baldwin AE, Vrana KE, Grigson PS (2008a) Heroin self-administration. I. Incubation of goal-directed behavior in rats. Pharmacol Biochem Behav 90:344-348.

Kuntz KL, Patel KM, Grigson PS, Freeman WM, Vrana KE (2008b) Heroin self-administration. II. CNS gene expression following withdrawal and cue-induced drug-seeking behavior. Pharmacol Biochem Behav 90:349-356.

LaLumiere RT, Kalivas PW (2008) Glutamate release in the nucleus accumbens core is necessary for heroin seeking. J Neurosci 28:3170-3177.

Langleben DD, Ruparel K, Elman I, Busch-Winokur S, Pratiwadi R, Loughead J, O'Brien CP, Childress AR (2008) Acute effect of methadone maintenance dose on brain FMRI response to heroin-related cues. Am J Psychiatry 165:390-394.

Lasseter HC, Ramirez DR, Xie X, Fuchs RA (2009) Involvement of the lateral orbitofrontal cortex in drug context-induced reinstatement of cocaine-seeking behavior in rats. Eur J Neurosci 30:1370-1381.

Liu XB, Jones EG (1996) Localization of alpha type II calcium calmodulindependent protein kinase at glutamatergic but not gamma-aminobutyric acid (GABAergic) synapses in thalamus and cerebral cortex. Proc Natl Acad Sci U S A 93:7332-7336.

Liu X, Ramirez S, Pang PT, Puryear CB, Govindarajan A, Deisseroth K, Tonegawa S (2012) Optogenetic stimulation of a hippocampal engram activates fear memory recall. Nature 484:381-385.

Lu L, Wang X, Wu P, Xu C, Zhao M, Morales M, Harvey BK, Hoffer BJ, Shaham Y (2009) Role of ventral tegmental area glial cell line-derived neurotrophic factor in incubation of cocaine craving. Biol Psychiatry 66:137-145. 
Lucantonio F, Stalnaker TA, Shaham Y, Niv Y, Schoenbaum G (2012) The impact of orbitofrontal dysfunction on cocaine addiction. Nat Neurosci $15: 358-366$

McFarland K, Kalivas PW (2001) The circuitry mediating cocaine-induced reinstatement of drug-seeking behavior. J Neurosci 21:8655-8663.

Morgan JI, Curran T (1991) Stimulus-transcription coupling in the nervous system: involvement of the inducible proto-oncogenes fos and jun. Annu Rev Neurosci 14:421-451.

Mullen RJ, Buck CR, Smith AM (1992) NeuN, a neuronal specific nuclear protein in vertebrates. Development 116:201-211.

Neisewander JL, Baker DA, Fuchs RA, Tran-Nguyen LT, Palmer A, Marshall JF (2000) Fos protein expression and cocaine-seeking behavior in rats after exposure to a cocaine self-administration environment. J Neurosci 20:798-805.

Noonan MP, Walton ME, Behrens TE, Sallet J, Buckley MJ, Rushworth MF (2010) Separate value comparison and learning mechanisms in macaque medial and lateral orbitofrontal cortex. Proc Natl Acad Sci U S A 107:20547-20552.

O’Brien CP, Childress AR, McLellan AT, Ehrman R (1992) Classical conditioning in drug-dependent humans. Ann N Y Acad Sci 654:400-415.

Paolone G, Conversi D, Caprioli D, Bianco PD, Nencini P, Cabib S, Badiani A (2007) Modulatory effect of environmental context and drug history on heroin-induced psychomotor activity and fos protein expression in the rat brain. Neuropsychopharmacology 32:2611-2623.

Paxinos G, Watson C (2005) The rat brain in stereotaxic coordinates, Ed 5. Amsterdam: Elsevier Academic.

Pennartz CM, Groenewegen HJ, Lopes da Silva FH (1994) The nucleus accumbens as a complex of functionally distinct neuronal ensembles: an integration of behavioural, electrophysiological and anatomical data. Prog Neurobiol 42:719-761.

Pickens CL, Airavaara M, Theberge F, Fanous S, Hope BT, Shaham Y (2011) Neurobiology of incubation of drug craving. Trends Neurosci 34:411-420.

Pickens CL, Cifani C, Navarre BM, Eichenbaum H, Theberge FR, Baumann MH, Calu DJ, Shaham Y (2012) Effect of fenfluramine on reinstatement of food seeking in female and male rats: implications for the predictive validity of the reinstatement model. Psychopharmacology 221:341-353.

Rogers JL, Ghee S, See RE (2008) The neural circuitry underlying reinstatement of heroin-seeking behavior in an animal model of relapse. Neuroscience 151:579-588.

Schoenbaum G, Eichenbaum H (1995) Information coding in the rodent prefrontal cortex. I. Single-neuron activity in orbitofrontal cortex compared with that in pyriform cortex. J Neurophysiol 74:733-750.

Schoenbaum G, Setlow B (2001) Integrating orbitofrontal cortex into prefrontal theory: common processing themes across species and subdivisions. Learn Mem 8:134-147.

Schoenbaum G, Shaham Y (2008) The role of orbitofrontal cortex in drug addiction: a review of preclinical studies. Biol Psychiatry 63:256-262.

Schoenbaum G, Setlow B, Ramus SJ (2003) A systems approach to orbitofrontal cortex function: recordings in rat orbitofrontal cortex reveal interactions with different learning systems. Behav Brain Res 146:19-29.
Schoenbaum G, Saddoris MP, Ramus SJ, Shaham Y, Setlow B (2004) Cocaine-experienced rats exhibit learning deficits in a task sensitive to orbitofrontal cortex lesions. Eur J Neurosci 19:1997-2002.

Schoenbaum G, Roesch MR, Stalnaker TA, Takahashi YK (2009) A new perspective on the role of the orbitofrontal cortex in adaptive behaviour. Nat Rev Neurosci 10:885-892.

Self DW, Nestler EJ (1998) Relapse to drug-seeking: neural and molecular mechanisms. Drug Alcohol Depend 51:49-60.

Sell LA, Morris J, Bearn J, Frackowiak RS, Friston KJ, Dolan RJ (1999) Activation of reward circuitry in human opiate addicts. Eur J Neurosci 11:1042-1048.

Sell LA, Morris JS, Bearn J, Frackowiak RS, Friston KJ, Dolan RJ (2000) Neural responses associated with cue evoked emotional states and heroin in opiate addicts. Drug Alcohol Depend 60:207-216.

Shaham Y, Shalev U, Lu L, De Wit H, Stewart J (2003) The reinstatement model of drug relapse: history, methodology and major findings. Psychopharmacology 168:3-20.

Shalev U, Morales M, Hope B, Yap J, Shaham Y (2001) Time-dependent changes in extinction behavior and stress-induced reinstatement of drug seeking following withdrawal from heroin in rats. Psychopharmacology (Berl) 156:98-107.

Shalev U, Grimm JW, Shaham Y (2002) Neurobiology of relapse to heroin and cocaine seeking: a review. Pharmacol Rev 54:1-42.

Shepard JD, Bossert JM, Liu SY, Shaham Y (2004) The anxiogenic drug yohimbine reinstates methamphetamine seeking in a rat model of drug relapse. Biol Psychiatry 55:1082-1089.

Van den Oever MC, Goriounova NA, Li KW, Van der Schors RC, Binnekade R, Schoffelmeer AN, Mansvelder HD, Smit AB, Spijker S, De Vries TJ (2008) Prefrontal cortex AMPA receptor plasticity is crucial for cueinduced relapse to heroin-seeking. Nat Neurosci 11:1053-1058.

Van den Oever MC, Lubbers BR, Goriounova NA, Li KW, Van der Schors RC, Loos M, Riga D, Wiskerke J, Binnekade R, Stegeman M, Schoffelmeer AN, Mansvelder HD, Smit AB, De Vries TJ, Spijker S (2010) Extracellular matrix plasticity and GABAergic inhibition of prefrontal cortex pyramidal cells facilitates relapse to heroin seeking. Neuropsychopharmacology 35:2120-2133.

Volkow ND, Fowler JS (2000) Addiction, a disease of compulsion and drive: involvement of the orbitofrontal cortex. Cereb Cortex 10:318-325.

Wikler A (1973) Dynamics of drug dependence. Implications of a conditioning theory for research and treatment. Arch Gen Psychiatry 28:611-616.

Wise RA, Hoffman DC (1992) Localization of drug reward mechanisms by intracranial injections. Synapse 10:247-263.

Wolf ME, Ferrario CR (2010) AMPA receptor plasticity in the nucleus accumbens after repeated exposure to cocaine. Neurosci Biobehav Rev 35:185-211.

Zhou W, Zhang F, Liu H, Tang S, Lai M, Zhu H, Kalivas PW (2009) Effects of training and withdrawal periods on heroin seeking induced by conditioned cue in an animal of model of relapse. Psychopharmacology 203: $677-684$. 